ИСМАИЛОВА АЙгюн Намиковна,

студентка образовательной программы бакалавриата «Зарубежное регионоведение» Восточного института - Школы региональных и международных исследований ДВФУ (г. Владивосток).

Электронная почта: ismailova.ana@students.dvfu.ru

ЗОЛОТУХИН Иван Николаевич,

канд. полит. наук, доцент кафедры международных отношений Восточного института - Школы региональных и международных исследований, ДВФУ (г. Владивосток).

Электронная почта: zolivnik@mail.ru.

\title{
Направления и динамика сотрудничества России и Вьетнама в сфере добычи углеводородов на современном этапе
}

\section{УДК 330.15}

\section{энергетическое}

сотрудничество, небтепереработка, добыча небти, добыча газа, российско-вьетнамское сотрудничество, проблемь сотрудничества
Для циттирования:

Исмаилова А. Н., Золотухин И. Н. Направления и динамика сотрудничества России и Вьетнама в сфере добычи углеводородов на современном этапе // Известия Восточного института. 2021. № 1. C. $82-88$. DOI https://doi.org/10.24866/2542$1611 / 2021-1 / 82-88$

\author{
DOI https://doi.org/10.24866/2542-1611/2021-1/82-88
}

В статье рассматривается динамика взаимоотношений Российской Федерации и Социалистической Республики Вьетнам в сфере освоения углеводородных месторождений и развития энергетики. На примере реализации конкретных проектов рассматривается и анализируется процесс двустороннего взаимодействия в рамках подписанных соглашений и актов, а также перспективы расширения нефтегазового сотрудничества, обозначенные на уровне глав государств. Обозначены результаты работы совместных предприятий, затронуты пути секторального развития и стоящие перед ними вызовы.

Российско-вьетнамские отношения носят дружественный характер и на протяжении более 50 лет характеризуются взаимопониманием и отсутствием серьезных внешнеполитических разногласий. Важным вектором двустороннего сотрудничества остаётся сфера добычи и обработки нефти и газа, которая даже в сложный период 1990-х гг., когда в российско-вьетнамских отношениях наблюдалось замедление темпов, сохранила перспективный характер.

Весомое положение в нефтегазовой отрасли СРВ занимает совместное предприятие (СП) России и Вьетнама «Вьетсовпетро», созданное в 1981 г., в структуру которого входит более 15 подразделений, занимающихся поиском, разведкой и добычей нефти и газа. За историю существования СП было проложено более 770 км трубопроводов, позволивших создать удобную транспортную инфраструктуру между всеми внутрипромысловыми объектами [9].

Из-за проблем, связанных с пандемией Covid-19, компания предприняла усилия по сокращению производственных затрат (более чем на 105 млн. \$) и расходов (на 17\%), а выручка от продажи нефти в 2020 г. составила всего около 1,11 млрд. $\$$, что составляет $81,1 \%$ от плана [1]. В то же время неизменными остаются задачи стратегии устойчивого развития СП «Вьетсовпетро» до 2030 г., такие как выработка финансовоэкономических механизмов, направленных на дальнейшее продолжение эффективных поисково-разведочных работ на континентальном шельфе Вьетнама, на территории России и других стран, в направлении диверсификации производствен- 
ной деятельности и источников финансирования, развития преимуществ накопленного опыта, имеющейся материально-технической базы и технико-технологической системы СП.

Нельзя отрицать готовность и активное сотрудничество с вьетнамской стороной ПАО «Газпром», которая получила участок для поиска углеводородов в заливе Винь Бак Бо в начале 2000-х гг., где впоследствии для бурения разведочных скважин были выбраны месторождения Бао Ден и Бао Ванг с суммарными запасами газа 300 млрд. куб. м. [14]. Газ из месторождения Бао Ванг, согласно Сочинскому меморандуму 2018 г., будет питать электростанцию, которую планируется построить в провинции Куангчи, где идет ускоренное формирование экономической зоны «Донг Нам» с планируемой промышленной, логистической и портовой инфраструктурой. Проект электростанции включен в государственный план развития электроэнергетики СРВ до 2030 г. [12].

В результате расширения сотрудничества ОАО «Газпром» и «PetroVietnam» было создано ООО «Газпромвьет», которое специализируется на добыче и обработке нефти в Нагумановском месторождении в Оренбургской области [3]. Вьетнамские компании получили приглашение работать на территории Северо-Пуровского месторождения на Ямале с запасом более чем 60 млрд. куб. м газа. С 2013 г. специализированная компания «Газпрома» «Gazprom EP International» и «Petrovietnam» начали вести совместную добычу газа и газового конденсата на шельфовых месторождениях Вьетнама «Мок Тинь» и «Хай Тхать» [7].

В 2008 г. зарегистрировано ООО «РУСВЬЕТПЕТРО», деятельность которого территориально обращена на Тимано-Печорскую нефтегазоносную провинцию, занимающую по запасам нефти 4 место в России. 29 октября 2020 г. предприятие достигло отметки 28 млн. тонн нефти [8]. Деятельность ООО «РУСВЬЕТПЕТРО» охватывает 4 блока, которые в сумме включают в себя более 10 месторождений. Особую роль играет выгодное географическое положение округа - вдоль побережья северо-востока Европейской части России, а это - близость Северного морского пути и европейских рынков сбыта. Недра округа привлекательны и тем, что степень выработанности разведанных запасов нефти достигла лишь 8\%, а свободного газа - 0,7\% [6, с. 4549]. ООО «РУСВЬЕТПЕТРО» открывают тендеры на бурение с целью поддержания добычи на месторождениях севера России. Ожидания серьёзного сокращения масштабов нефтедобычи из-за распространения корона вирусной инфекции не подтвердились. В сентябре 2020 г. компания сообщила о добыче нефти почти на 2,2 млн. тонн за период с января по отчетный месяц, что лишь на 0,4 млн. тонн меньше, чем в 2019 г. В то же время, из-за нарушений ограничительных норм, к ноябрю 2020 г. количество подтвержденных случаев заражения Covid-19 на предприятии выросло почти на 50\% [15].

На встрече глав государств в 2018 г. Президент Российской Федерации В. В. Путин и Генеральный Секретарь Социалистической Республики Вьетнам Нгуен Фу Чонг отметили переход сотрудничества в энергетической сфере на качественно новый уровень [11]. В ходе диалога лидеры двух стран подтвердили готовность к созданию благоприятных условий с целью расширения деятельности российских и вьетнамских нефтегазовых компаний на территориях двух государств, к налаживанию сотрудничества на таких направлениях, как нефтепереработка и нефтехимия, строительство газовых электростанций, которые имеют большой потенциал к развитию. 
Планируется также увеличить объёмы поставок во Вьетнам сжиженного природного газа и создать соответствующую инфраструктуру для его переработки и сбыта, производство газомоторного топлива и последующего его использования или экспорта.

Кроме того, лидеры обоих государств отметили перспективный характер сотрудничества в сфере электроэнергетики, указав на преимущества привлечения заинтересованных российских компаний к восстановлению и совершенствованию созданных при содействии СССР и потерянных при разрыве партнёрских отношений в конце 1990-х гг. объектов. На данный момент большинство российских компаний предпочитают инвестировать в развитие компаний, территориально находящихся во Вьетнаме. Укреплению российских компаний в СРВ способствует представление для Вьетнама возможности разрабатывать месторождения углеводородов на российской территории. Это является одним их условий, поставленных вьетнамской стороной для российских компаний, которые выражают желание сотрудничать и получить доступ к ресурсам континентального шельфа в Южно-Китайском море (ЮКМ).

Помимо поддержки совместных предприятий по добыче и обработке ресурсов, исходящей непосредственно от стран-создателей, такие общие проекты пользуются популярностью для инвестиций других государств. Созданный в 2002 г. концерн трёх сторон в составе «Зарубежнефти», «Петровьетнама» и японской компании «Идемицу» предполагал разработку месторождения 09-3, расположенного около Вунгтау. СП «Вьетсовпетро» принимало участие в реализации проектов нефтегазового сектора на условиях раздела продукции в районе Мьянмы и Туниса.

В мае 2019 г. премьер-министры России и Вьетнама Дмитрий Медведев и Нгуен Суан Фук договорились обеспечивать благоприятные условия для эффективной реализации на территории наших стран совместных проектов - «Газпром», «Роснефть», «Зарубежнефть», «Новатэк», «Петровьетнам» и др. По итогам переговоров был подписан Меморандум о взаимопонимании между ПАО «НОВАТЭК» и Народным комитетом провинции Ниньтхуан по развитию интегрированного проекта электрогенерации с использованием сжиженного природного газа в коммуне Кана. Генеральным директором АО «Зарубежнефть» Сергеем Кудряшовым был заключён ряд договоров с вьетнамскими коллегами: соглашение о переуступке доли между PVEP Corporation и AО «Зарубежнефть» в отношении Блока 09-2/09 шельфа СРВ, соглашение о намерениях по дальнейшему сотрудничеству в области совместной реализации нефтегазовых проектов на территории России Вьетнама и третьих стран, соглашение о сотрудничестве между $\mathrm{AO}$ «Зарубежнефть» и крупнейшим инвестиционным холдингом СРB «Т\&T Group» в области развития возобновляемых источников энергии [4].

В 2020 г. исполнилось 70 лет установления дружественных отношений между странами. Летом, несмотря на пандемию коронавируса, главы двух государств обсудили новые направления в сфере энергетики как в рамках действующих программ по добыче углеводородов, так и в сферах электрогенерации и мирного атома [10]. Последние две сферы могут стать основой двустороннего энергетического сотрудничества. Хотя вьетнамское руководство отказалось от строительства 
АЭС в провинции Ниньтхуан при поддержке России, тем не менее российская сторона остаётся наиболее значимым партнёром, способным оказать помощь в реализации вьетнамской программы ядерной энергетики. Дополнительный импульс формированию новых российско-вьетнамских совместных проектов может дать развитие во Вьетнаме регенеративных источников энергии, долю которых в суммарном энергопотреблении правительство планирует увеличивать. $[5$, c. 150$]$

2020 г. принёс развитию мировой экономики множество испытаний, обнажив ряд проблем нефтесервисного сегмента. Однако волатильность цен на нефть и конъюнктуры нефтегазового рынка не привели к кардинальным изменениям в российско-вьетнамских отношениях, двустороннее сотрудничество в нефтегазовой сфере остаётся устойчивым. За последние годы странам удалось расширить диапазон взаимодействия. Речь идёт в том числе и об изменении нормативноправовой базы двух стран, что позволило открыть новые выходы для разработки и применения налоговых льгот для внутренних или иностранных инвесторов. Изменение налоговой политики двух стран поможет сделать совместные проекты привлекательными для инвесторов своей особой прозрачностью функционирования.

Тот факт, что Россия взяла на себя обязательства продолжать проекты добычи нефти и газа на континентальном шельфе, который Ханой считает своей территорией, свидетельствует о готовности России развивать отношения с Вьетнамом вне зависимости от внешних факторов, таких как препятствия со стороны Китая энергетическому сотрудничеству двух стран в спорных участках ЮжноКитайского моря. В то же время Москве следует соблюдать осторожность по данному вопросу и учитывать возможность изменения позиций обоих стратегических партнёров в будущем.

Российско-вьетнамское сотрудничество в нефтегазовой сфере носит характер взаимопроникающей интеграции госкорпораций, системного участия российских компаний в развитии базовой энергетической отрасли СРВ, а также формирования цены не на рыночных принципах для добываемого совместными предприятиями газа [2].

Добыча углеводородов остаётся одной из самых выгодных для обеих стран сфер сотрудничества, привлекательной для инвестиций из-за рубежа. В то же время Ханой заинтересован в расширении числа иностранных партнёров для развития нефтегазовой отрасли не только с целью найти более выгодные условия, но и для интернационализации проектов, чтобы ослабить накал ситуации в ЮКМ. Такая политика, создавая конкуренцию за участие во вьетнамских нефтегазовых проектах, может отразиться на содержании партнёрских отношений России и Вьетнама. Нельзя сбрасывать со счетов и позицию США, заинтересованных в ослаблении влияния Москвы в Юго-Восточной Азии, в том числе в уменьшении ее участия в добыче нефти и газа на территории континентального шельфа ЮКМ [13, с. 139-140].

Таким образом, многолетний опыт сотрудничества СССР, а впоследствии России с Вьетнамом в сфере нефте и газодобычи, а также сохраняющаяся рентабельность совместных предприятий позволяют оценивать современное состояние двусторонних отношений в нефтегазовой отрасли со сдержанным оптимизмом. Однако благоприятный сценарий развития нефтегазового сотрудничества России и Вьетнама 
всё больше зависит от взаимовыгодного характера реализуемых и планируемых проектов, а не от обоюдной благожелательности руководства двух стран. Показательный характер имеет заинтересованность Ханоя в привлечении большего количества иностранных инвесторов в развитие своей нефтегазовой сферы, что может привести к существенному сокращению в ней удельного веса российских компаний. Значимым фактором российско-вьетнамского сотрудничества продолжают оставаться дружественные отношения и тесные политические связи двух стран, однако политические договорённости не всегда гарантируют результат, примером чему можно назвать безрезультатные переговоры России с Вьетнамом о строительстве АЭС.

\section{Литература}

1. Вьетнам уходит от нефтегазового диктата Запада с помощью российских госкомпаний // Интернет-портал «Однако». 25.06.2014. URL http://www.odnako. org/blogs/vetnam-uhodit-ot-neftegazovogodiktata-zapada-s-pomoshchyu-rossiyskihgoskompaniy/ (дата обращения 30.11.2020).

2. Вьетнам. Нефть, газ, уголь // Интернет-портал «Polpred». Новости. Обзор СМИ. 21.12.2020. URL https://polpred.com/news/?prv_ list $=\& \mathrm{~ns}=1 \& \mathrm{wh}$ ous er $=\& \mathrm{img}=\& \mathrm{cnt}$ and $=\&$ person_id $=\& 0 s \% 5 \mathrm{~B} 8 \% 5 \mathrm{D}=$ on $\& \mathrm{cs} \% 5$ $\mathrm{B} 34 \% 5 \mathrm{D}=$ on \&searchtext $=\&$ fulltext $=$ clr\&fullt ext $=$ on \&beg $=\&$ end $=\&$ word $=$ \&period $=\&$ peri od_count=1\&sortby=\&pl= (дата обращения 26.12.2020).

3. «Газпром» и «Петровьетнам» развивают сотрудничество. // Интернет-портал «ПРАЙМ. Агентство экономической информации». 03.10.2013. URL https://1 prime. ru/press_release/20131003/767445634.html (дата обращения 20.11.2020).

4. Дмитрий Медведев провёл переговоры с Премьер-министром Вьетнама Нгуен Суан Фуком // Интернет-портал Правительства России. 22.05.2019. URL http:// government.ru/news/36753/\#36753=35:1:9g U,42:20:H71 (дата обращения 05.12.2020).

5. Золотухин И. Н., Цзя Су Ян. Развитие ядерной энергетики в Юго-Восточной Азии: история, тенденции, перспективы // Ойкумена. Регионоведческие исследования. 2018. № 4. С. 144-157. DOI 10.24866/1998-6785/2018-4/145-157

6. Карапетян К. С. Сотрудничество России и Вьетнама в нефтегазовой сфере // Вестник РУДН, серия «Международные отношения». 2012. №2. С. 45-49.

7. Кузьмина Мария. Россия поможет Вьетнаму с газом // Интернет-портал «Русская планета». 7.09.2018 URL https://rusplt.ru/sub/economy/rossiyapomojet-vetnamu-34935.html ?utm source $=$ yxnews \&utm_medium $=$ desktop (дата обращения 25.11.2020).

8. ООО «СК "РУСВЬЕТПЕТРО"» достигло отметки в 28 миллионов тонн добытой нефти // Интернет-портал РПВ. 30.10.2020. URL https://www.rvpetro. $\mathrm{ru} / \mathrm{presscenter/oоo-ск-русвьетпетро-}$ достигло-отметк-8/ (дата обращения 10.12.2020).

9. ООО «РУСВЬЕТПЕТРО». Деятельность // Интернет-портал PПВ. URL https://www.rvpetro.ru/about/activity/ (дата обращения 12.12.2020).

10. Россия и Вьетнам обсудили совместные инвестпроекты // Интернетпортал «RusCable.Ru». 31.08.2020. URL https://mobile.ruscable.ru/news/2020/8/31/ Rossiya_i_Vyetnam_obsudili_sovmestnye_ investproekt/ (дата обращения 07.12.2020).

11. Совместное заявление по итогам официального визита Генерального секретаря Центрального комитета Коммунистической партии Вьетнама Нгуен Фу Чонга в Российскую Федерацию. Президент России // Официальный сайт Президента России. 8.09.2018. URL http://www. kremlin.ru/supplement/5338 (дата обращения 24.11.2020).

12. СП «Вьетсовпетро». Выдающиеся достижения // Интернет-портал «Вьетсовпетро». URL https://www.vietsov.com.vn/ Rus/Pages/Environment.aspx (дата обраще- 
ния 01.12.2020).

13. Федоров Н. В. Участие России в нефтегазовых проектах на континентальном шельфе Вьетнама: проблемы и перспективы // Юго-Восточная Азия: актуальные проблемы развития. 2018. № 4 (41). С. 129143.

14. Gazprom EP International. История компании // Интернет-портал ПАО «Газпром». URL http://www.gazprominternational.com/about/managers/ (дата об- ращения 21.11.2020).

15. Russian-Vietnamese oil venture opens drilling tenders despite looming coronavirus restrictions // Upstream. Energy Explores (сайт). 30 October 2020. URL https://www. upstreamonline.com/coronavirus/russianvietnamese-oil-venture-opens-drillingtenders-despite-looming-coronavirusrestrictions/2-1-903767 (дата обращения 10.12.2020).

\section{Aigiun N. ISMAILOVA,}

Undergraduate Student in the field of regional studies, Oriental Institute - School of Regional and International Studies, Far Eastern Federal University (Vladivostok, Russia).

E-mail: ismailova.ana@students.dvfu.ru

\section{Ivan N. ZOLOTUKHIN,}

Ph. D. (in Political Science), Assosiate Professor, International Relations Department, Oriental Institute - School of Regional and International Studies, Far Eastern Federal University (Vladivostok, Russia).

E-mail: zolivnik@mail.ru

\section{Directions and Dynamics of cooperation between Russia and Vietnam in the Field of Hydrocarbon Production at the Present Stage}

The article examines the dynamics of relations between the energy cooperation, Russian Federation and the Socialist Republic of Vietnam in the exploitation of hydrocarbon deposits and energy development. On the example of the implementation of specific projects, the process of bilateral interaction within the framework of signed agreements and acts, as well as the prospects for expanding oil and gas cooperation, identified at the level of heads of state, are considered and analyzed. The author clarifies the peculiarities of oil refining, oil production, gas production, Russian-Vietnamese cooperation, cooperation in russo-vietnamese relations in the field of oil and cooperation problems gas production pointing out that it functions not only because of profitability and mutually beneficial nature of joint ventures but also due to benevolent political environment which has been formed between the two states. The results of the work of joint ventures are outlined, the ways of sectoral development and the challenges they face are touched upon.

For citation: Ismailova A. N., Zolotukhin I. N. Directions and Dynamics of cooperation between Russia and Vietnam in the Field of Hydrocarbon Production at the Present Stage // Oriental Institute Journal. 2021. № 1. P. 82-88. DOI https://doi.org/10.24866/2542-1611/2021-1/82-88 


\section{References}

1. V'etnam ukhodit ot neftegazovogo diktata Zapada s pomoshh'yu rossijskikh goskompanij // Internet-portal "Odnako». 25.06.2014. URL http://www.odnako.org/ blogs/vetnam-uhodit-ot-neftegazovogodiktata-zapada-s-pomoshchyu-rossiyskihgoskompaniy/ (data obrashheniya 30.11.2020).

2. V'etnam. Neft', gaz, ugol' // Internet-portal «Polpred». Novosti. Obzor SMI. 21.12.2020. URL https://polpred.com/news / ? prv_ list $=\& \mathrm{~ns}=1 \& \mathrm{whouser}=\& \mathrm{img}=\& \mathrm{cnt}$ and $=\&$ person $\_\mathrm{id}=\&$ os $\% 5 \mathrm{~B} 8 \% 5 \mathrm{D}=$ on $\& \mathrm{cs}$ $\% 5 \mathrm{~B} 34 \% 5 \mathrm{D}=$ on \&searchtext $=\&$ fulltext $=\mathrm{clr}$ \&fulltext $=$ on \&beg $=$ \&end $=\&$ word $=$ \&perio $\mathrm{d}=\&$ period_count $=1 \&$ sortby $=\& \mathrm{pl}=\quad$ (data obrashheniya 26.12.2020).

3. «Gazprom» i «Petrov'etnam» razvivayut sotrudnichestvo. // Internetportal «PRAJM. Agentstvo ehkonomicheskoj informatsii». 03.10.2013. URL https://1 prime. ru/press_release/20131003/767445634.html (data obrashheniya 20.11.2020).

4. Dmitrij Medvedev provyol peregovory s Prem'er-ministrom V'etnama Nguen Suan Fukom // Internet-portal Pravitel'stva Rossii. 22.05.2019. URL http://government.ru/new s/36753/\#36753=35:1:9gU,42:20:H71 (data obrashheniya 05.12.2020).

5. Zolotukhin I. N., TSzya Su YAn. Razvitie yadernoj ehnergetiki v YUgoVostochnoj Azii: istoriya, tendentsii, perspektivy // Ojkumena. Regionovedcheskie issledovaniya. 2018. № 4. S. 144-157. DOI 10.24866/1998-6785/2018-4/145-157

6. Karapetyan K. S. Sotrudnichestvo Rossii i V'etnama v neftegazovoj sfere // Vestnik RUDN, seriya «Mezhdunarodnye otnosheniya». 2012. №2. S. 45-49.

7. Kuz'mina Mariya. Rossiya pomozhet V'etnamu s gazom// Internet-portal «Russkaya planeta». 7.09.2018 URL https://rusplt.ru/sub/ economy/rossiya-pomojet-vetnamu-34935. html ? utm_source=yxnews \&ut m _ medium=desktop (data obrashheniya 25.11.2020).

8. OOO «SK "RUSV'ETPETRO"» dostiglo otmetki v 28 millionov tonn dobytoj nefti // Internet-portal RPV. 30.10.2020. URL https://www.rvpetro.ru/presscenter/ ooo-sk-rusv'etpetro-dostiglo-otmetk-8/ (data obrashheniya 10.12.2020).

9. OOO «RUSV'ETPETRO». Deyatel'nost' // Internet-portal RPV. URL https://www.rvpetro.ru/about/activity/ (data obrashheniya 12.12.2020).

10. Rossiya i V'etnam obsudili sovmestnye investproekty // Internet-portal «RusCable. Ru». 31.08.2020. URL https://mobile.ruscable. ru/news/2020/8/31/Rossiya_i_Vyetnam_ obsudili_sovmestnye_investproekt/ (data obrashheniya 07.12.2020).

11. Sovmestnoe zayavlenie po itogam ofitsial'nogo vizita General'nogo sekretarya TSentral'nogo komiteta Kommunisticheskoj partii V'etnama Nguen $\mathrm{Fu}$ CHonga v Rossijskuyu Federatsiyu. Prezident Rossii // Ofitsial'nyj sajt Prezidenta Rossii. 8.09.2018. URLhttp://www.kremlin.ru/supplement/5338 (data obrashheniya 24.11.2020).

12. SP «V'etsovpetro». Vydayushhiesya dostizheniya // Internet-portal «V'etsovpetro». URL https://www.vietsov.com.vn/Rus/ Pages/Environment.aspx (data obrashheniya 01.12.2020).

13. Fedorov N. V. Uchastie Rossii v neftegazovykh proektakh na kontinental'nom shel'fe V'etnama: problemy i perspektivy // YUgo-Vostochnaya Aziya: aktual'nye problemy razvitiya. 2018. № 4 (41). S. 129143.

14. Gazprom EP International. Istoriya kompanii // Internet-portal PAO «Gazprom». URL http://www.gazprom-international. com/about/managers/ (data obrashheniya 21.11.2020).

15. Russian-Vietnamese oil venture opens drilling tenders despite looming coronavirus restrictions // Upstream. Energy Explores (sajt). 30 October 2020. URL https://www. upstreamonline.com/coronavirus/russianvietnamese-oil-venture-opens-drillingtenders-despite-looming-coronavirusrestrictions/2-1-903767 (data obrashheniya 10.12.2020). 